\title{
Prevalence of radiographic markers of femoroacetabular impingement in asymptomatic adults
}

\section{Prevalência dos achados radiográficos de impacto femoroacetabular em adultos assintomáticos}

Rodrigo Benedet Scheidt'; Carlos Roberto Galia ; Cristiano Valter Dieseli; Ricardo Rosito'; Carlos Alberto de Souza Macedo

\author{
A $B$ S S T T R A C C T
}

\begin{abstract}
Objective: to determine the prevalence of radiographic signs of femoroacetabular impingement (FAl) in asymptomatic adults and correlate them with data from physical examinations. Methods: We conducted a cross-sectional study with 82 asymptomatic volunteers, 164 hips, between 40 and 60 years of age, selected by convenience. They were submitted to anamnesis and clinical examination of the hip, anteroposterior (AP) pelvis radiographs with three incidences, Dunn $45^{\circ}$ and Lequesne false profile of each hip, to measure the variables. We measured the alpha angle, anterior offset of the femoral neck, cervical diaphyseal angle, CE angle of Wiberg, acetabular index, Sharp angle, and the crossing, ischial spine and posterior wall signs. Results: our sample consisted of $66 \%$ women, mean age of 50.4 years. The average alpha angle was $45.10^{\circ}, \mathrm{SD}=8.6$. One quarter of the hips showed alpha angle greater than or equal to $50^{\circ}$; among men the prevalence was $34 \%$, and among women, $11 \%$. We found indicative radiographic signs of femoroacetabular impingement in $42.6 \%$ of hips, whether femoral or acetabular, and the increased alpha angle was related to the decrease in hip internal rotation $(p<0.001)$. Conclusion: the radiographic findings of femoroacetabular impingement in asymptomatic patients were frequent in the studied sample. The increase in alpha angle was associated with decreased internal rotation.
\end{abstract}

Key words: Femoroacetabular impingement. Hip. Radiography. Cross-sectional studies. Prevalence.

\section{INTRODUCTION}

$P^{r}$ rimary or idiopathic Osteoarthritis (OA) of the hip accounts for approximately $30 \%$ to $40 \%$ of cases 1 , and the secondary, resulting from proximal femur epiphysiolysis, Legg-Calvé-Perthes disease, avascular necrosis among others, the remaining ${ }^{1,2}$.

Factors related to OA etiology are genetic, structural, morphological and biomechanical. Since 1976, Solomon had reported that hip OA was always associated with an abnormality, even if subtle, of the joint ${ }^{3}$. However, until today the exact pathogenesis of primary OA has not been established ${ }^{4-8}$. According to Bardakos et al., the etiology of osteoarthritis of the hip remains an enig$\mathrm{ma}^{9}$.

In the last decade there was an increase in the scientific literature regarding the etiology of primary osteoarthritis, supporting the hypothesis that small changes in the morphology of the hip could cause mechanical damage to the joint, resulting in its wear over time ${ }^{1,10}$. A spinal deformity in the anterolateral head neck junction of the femur and excessive anterior acetabular coverage correspond to those deformities. The term Femoroacetabular Impingement (FAl) would therefore translate the mechanism by which these morphological changes could cause damage to the hip joint, culminating in OA.

The FAl is puzzling because the mere presence of an sole lesion, whether Came or Pincer type, is not sufficient for the development of OA of the hip, which has been observed in patients who have these deformities bilaterally, but with only one symptomatic hip ${ }^{1,11}$. What is reported on the findings of many papers on FAl is that follow-up studies are needed to provide information about its natural history ${ }^{3,12,13}$. The most renowned authors on the subject state that there is no information about the natural course of the more subtle femoral and acetabular deformities, such as those present in FAl, and that only with investments, studies and cohorts it will be possible to determine the real impingement of $\mathrm{FAl}^{12}$. The knowledge about the etiology and natural history of primary OA of the hip is still controversial 1,13 .

This uncertainty about the prevalence of these "deformities" related to the FAl in the general population, as well as the natural history of Came and Pincer types alterations in asymptomatic patients, and the real contribution of these changes to the development of hip OA led us to the realization this work. 
This research aims to assess the prevalence of radiographic findings of femoroacetabular impingement in asymptomatic adult patients.

\section{METHODS}

This was a descriptive, cross-sectional study, conducted in the outpatient clinic of the Department of Orthopaedics, Clinics Hospital of Porto Alegre (HCPA). The sample consisted of 82 volunteers (164 hips), aged between 40 and 60 years, asymptomatic as for the hip joints and lumbar spine, with no history of any disease in this region. The sample was selected for convenience, after the dissemination of the research in the HCPA. This study was approved by the Ethics Committee of the HCPA - Protocol number 09-137.

We excluded Individuals with a history of disease or previous treatment on the hips or the lumbar spine, history of rheumatic diseases and those with inadequate radiographs. Radiographs were strictly controlled by the obturator foramen index (OFI) of Tönnis, and the pelvic tilt, by the symphysis-sacrococcygeal joint distance ${ }^{14}$. Women of childbearing potential who were not using any contraceptive method and who did not know the date of the last menstrual period were also excluded to avoid radiation exposure in possible pregnant women. Those who did not agree with the Terms of the Free and Informed Consent did not participate in the study either.

All participants underwent an interview and physical examination, performed by the same doctor. Range of motion of both hips was assessed and then applied the FAl maneuver or provocative test, with flexion, adduction and internal rotation ${ }^{15}$. The maneuvers were performed with the patient in supine position, with special attention to the pelvic movement, the degree of amplitude being determined at the first hint of mobilization of the hip. The examination respected the following sequence: flexion, internal and external rotation with the hip and knee flexed at 90 degrees, abduction and adduction with the hip in a neutral position. The hip extension was measured with the participant in the prone position, with a resident of the Orthopedics Service stabilizing the pelvis and the researcher applying the extension. The measurements were performed with a universal, double-angled goniometer, millimetered in transparent plastic.

After clinical examination, participants underwent anterior posterior (AP) pelvis radiography in the standing position, Lequesne false profile and Dunn $45^{\circ}$ incidence.

Radiographs were performed by the same X-ray technician, who received specific training in a referral center in musculoskeletal radiology prior to the commencement of the research.

The anterior posterior radiograph was performed in the standing position, with the $\mathrm{X}$-ray tube positioned at a distance of $120 \mathrm{~cm}$ from the film, centered at the intersection of an imaginary line between the anterior superior iliac spines and a vertical line through the center of, about two centimeters proximal to, the pubic symphysis ${ }^{5}$.

In this same incidence we controlled the quality of radiographs as for the rotation through the obturator foramen index (OFI) described by Tönnis, where the greatest horizontal axis of the right obturator foramen is divided by the left- most horizontal axis, having an acceptable result between 0.56 and 1.8 for measurement of the acetabular landmarks ${ }^{14}$. We adopted a less tolerant range, and included only those radiographs with OFI between 0.8 and 1.2. To control pelvic tilt, we observed the distance from the top surface of the pubic symphysis to the sacrococcygeal joint, considered ideal between one and three centimeters ${ }^{4}$. In this incidence, when the quality criteria were not fulfilled, we discarded the measures relating to the analysis of the acetabulum and pelvis; however, the findings regarding the proximal femur were not discarded because they are not influenced by pelvic rotation or tilt.

The false profile incidence of Lequesne and Sezé was performed according to the description of Lequesne ${ }^{16}$. Radiographs considered appropriate were those showing a distance corresponding to the diameter of a femoral head between the two hips.

The profile of Dunn at $45^{\circ}$ was obtained with the patient supine with the hips to be $x$-rayed at $45^{\circ}$ flexion and $20^{\circ}$ abduction in neutral rotation, with the $X$-ray tube directed at the inguinal crease, perpendicular to table, at a distance of $100 \mathrm{~cm}^{8}$ (Figure 1).

The variables analyzed in the AP radiographs were as follows: cervical-diaphyseal angle, sphericity of the femoral head, angle of Sharp, center edge angle of Wiberg, acetabular index, index of extrusion of the femoral head, acetabular depth and minimum joint space. We also investigated the presence of the crossing sign, suggesting a partial overcoverage, the ischial spine signal, denoting

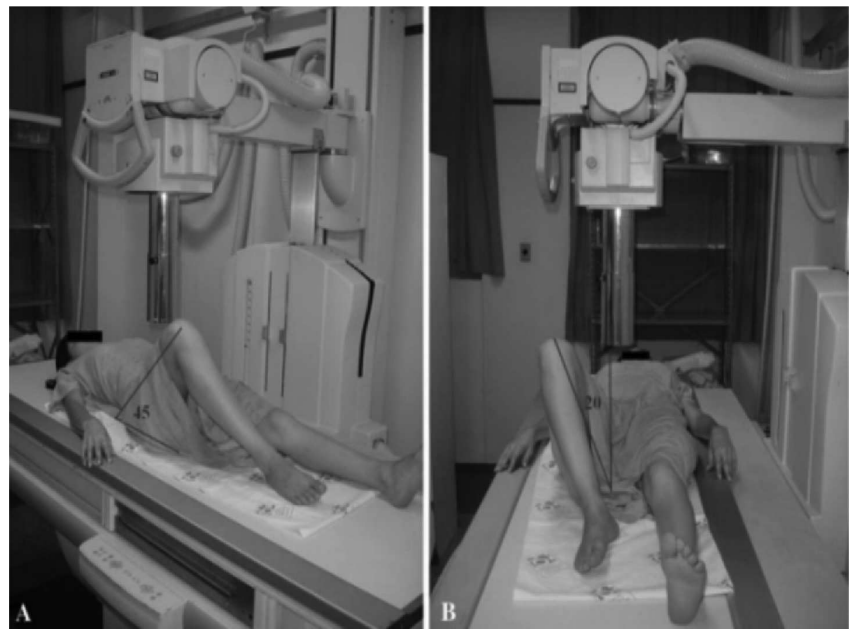

Figure 1 - Positioning the patient for the Dunn $45^{\circ}$ radiographic incidence. 
acetabular retroversion, and the posterior wall sign, suggesting posterior coverage disability.

In the false profile incidence of Lequesne, we measured the anterior cover angle to assess a possible reduction of the joint posterior-inferior space or also the countercoup injury, present in the Pincer-type FAl ${ }^{16,17}$.

In the Dunn $45^{\circ}$ incidence we measured the alpha angle as described by Nötzli, to ascertain the anterior concavity of the head-neck junction. The measure was obtained by the intersection of two lines: the first runs along the axis of the femoral neck and the second connecting the center of the femoral head to the point where the anterior cortex of the head-neck junction diverges from the perfect circle that the femoral head should form following the concentric angles of Moose ${ }^{18}$. Another measure in this incidence was performed the anterior offset of the femoral neck, which is the distance between a line parallel to the anterior cortex of the femoral neck and another drawn parallel to the first, at the foremost part of the femoral head in the Dunn $45^{\circ}$ incidence.

The measurements were performed using a transparent millimetered ruler, with the center of the femoral head being determined by following the concentric angles of Moose.

Qualitative variables were described as frequency and percentage. Quantitative ones were describe as minimum, maximum, mean and standard deviation. We used The Kolmogorov-Smirnoff test to analyze the distribution of variables. We use the Pearson linear correlation for variables with normal or symmetrical distribution, and the Spearman method for the asymmetric. For independent samples we used the Student's t test to compare means. Statistical significance was considered at $p$ value $<0.05$.

\section{RESULTS}

The study included 82 subjects (164 hips), of which 28 (34\%) were men and 54 (66\%) women. Ages ranged from 40 to 60 years, with a mean of 50.4. Three patients (3.7\%) had inadequate AP radiographs, according to the applied criteria ${ }^{14}$.

The alpha angle ranged from 32 to 74 degrees, the most frequent values ranging between 35 and 50 degrees (Figure 2).

The average alpha was 45 degrees, with $S D=8.6$. Alpha angles greater than or equal to 50 degrees were found in 41 hips (25\%). Among men the average was 47.52 degrees, and 43.85 in women. This difference was statistically significant $(p=0.028)$. Of the 56 male hips, 19 (34\%) had alpha angles greater than or equal to 50 degrees, and among the 108 women, only $12(11.11 \%)$ had the alpha in this range.

Increasing the alpha angle was associated with a decrease in internal rotation (RI) of the hip, $(r=-0355$, $p<0.001)$. The internal rotation in those with alpha angles greater than or equal to $50^{\circ}$ was significantly lower than those who had alpha $<50^{\circ}(p=0.002)$.

When analyzing the radiographs as for the deformity presented, $42.6 \%$ had some sort of deformity suggestive of FAl. The deformity characterizing the Cametype impingement was found in 41 hips (25\%), the Pincer deformity in 20 cases (12.65\%), and mixed type in six cases (3.7\%). The remaining 96 hips (58.5\%) showed no radiographic changes suggestive of FAl.

The prevalence of variables denoting Pincer-type impingement and acetabular retroversion are shown in table 1.

The femoral anterior head-neck offset, the angle of anterior acetabular coverage (AAC) and further measures analyzed are described in Table 2.

On physical examination, variables of range of motion (ROM), mean and standard deviation are shown in Table 3.

Hip flexion was not related to the angle of the anterior acetabular coverage (AAC) $(p=0.243)$ nor with the sign of the cross $(p=0.822)$. The femoral anterior headneck offset showed a negative correlation with the hip internal rotation, though not statistically significant $(p=0.889)$.

\section{DISCUSSION}

We present results from 82 individuals, 164 hips, two thirds of the sample being female (66\%). This disparity probably occurred because the samples have been selected for convenience, and we know that women are more concerned and seeking more health services than men.

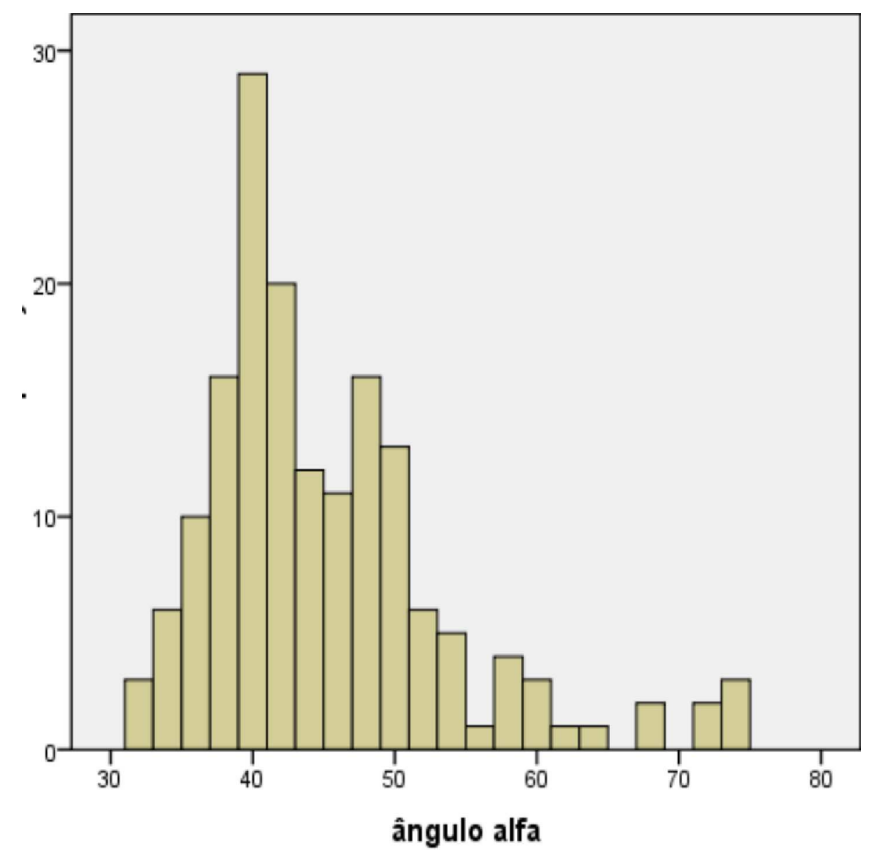

Figure 2 - Distribution of the alpha angle values according to frequency. 
Table 1 - Radiographic findings of Pincer-type impingement and acetabular retroversion in the evaluated hips.

\begin{tabular}{lcc}
\hline Radiographic & Alteration & Absolute \\
\hline Deep thigh & 120 & Prevalence $(\%)$ \\
Crossing sign & 20 & 76,0 \\
Posterior wall Sign & 58 & 12,6 \\
Ischial spine Sign & 47 & 36,7 \\
\hline
\end{tabular}

Note: In the radiographic assessments of the pelvis and acetabulum only 158 hips were considered because six of them were excluded due to image rotation.

Table 2 - Values of measures of acetabular and femoral angles.

\begin{tabular}{lcrr}
\hline Variable & Minimum/Maximum & Average & SD \\
\hline Cervical-diaphyseal angle & $116 / 146$ & 131.00 & 6.45 \\
Center edge angle & $20 / 56$ & 33.85 & 7.10 \\
Acetabular index & $-11 / 14$ & 2.27 & 5.28 \\
Femoral head extrusion index & $-6 / 27$ & 11.11 & 6.15 \\
Angle of anterior acetabular coverage & $12 / 56$ & 34.25 & 8.3 \\
Sharp angle & $28 / 49$ & 39.43 & 4.08 \\
Acetabular depth & $25 / 44$ & 33.86 & 3.75 \\
Anterior offset & $1 / 16$ & 9.22 & 2.46 \\
Minimum articular space & $2 / 7$ & 3.8 & -
\end{tabular}

SD: Standard Deviation.

Table 3 - Values of range of motion (ROM) of the hip.

\begin{tabular}{lrcc}
\hline Movement & ROM minimum-maximam (degrees) & Average (degrees) & SD \\
\hline Flexion & $90 / 150$ & 115.3 & 9.21 \\
Internal rotation & $5 / 45$ & 25.90 & 7.07 \\
External rotation & $15 / 45$ & 29.16 & 5.95 \\
Abduction & $20 / 55$ & 35.63 & 5.80 \\
Abduction & $20 / 40$ & 35.63 & 3.94 \\
Extension & $10 / 30$ & 17.14 & 4.71 \\
\hline
\end{tabular}

SD: Standard Deviation

We had losses due to the rotation of the AP pelvis radiographs (OFI $<0.8$ and/or $>1.2)$ in $3.7 \%$ of cases (three individuals). However, the measures concerning the proximal femur were maintained because they are not influenced by the pelvic rotation, as described by Siebenrock ${ }^{19}$. Our loss was lower than the larger cohort followed up on the subject in Copenhagen, with radiographic loss of $4.5 \%$ due to pelvic rotation ${ }^{20}$.

The average alpha angle of the sample was 45.10 degrees. Despite the large variation found, $32-72^{\circ}$, we believe that the average found was not higher only because two thirds of the sample were women, and it is known that these have an average alpha lower than men do. Nötzli found an average of 42 degrees in the control group and in 74 cases, determining a cutoff point of 50 degrees. Other authors describe averages between 42 and 52 10,13,21. However, due to the large variation of alpha in normal, asymptomatic patients, there are few studies that have described a normal alpha up to 60 to 62 degrees ${ }^{11,13,22}$, others even ${ }^{9}$ to 67 , ie, there has been no consensus as for the normal alpha angle in the general population. Pollard et al. questioned the study of Nötzli, putting in doubt whether hips with alpha greater than 50 degrees should be considered pathological, and suggest an alpha threshold of 63 degrees $^{13}$. Others describe the normal alpha as $60^{\circ 11}$. Our suggestion is that the alpha angle, mostly in men, have increased their cutoff value proposed by Nötzli. Going against the trend of increase of the alpha angle's upper limit, Neumann et al. published an interesting article where they measured the average alpha angle necessary to avoid bone impingement and obtain an internal rotation from 20 to $25^{\circ}$ at $90^{\circ}$ flexion, and found that an alpha of $43^{\circ}$ would be required ${ }^{23}$.

The mean alpha angle among men was 47.52 and 43.85 degrees among women, similar to the averages found by Toogood et al. in his work analyzing 375 femurs 
stored at the Museum of Natural History of Cleveland in the United States ${ }^{21}$. This difference was statistically significant $(p=0.028)$. The average alpha in men was significantly higher, since the Came-type deformity is more

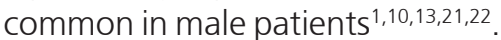

Of the 164 hips analyzed, 25\% (41 hips) had alpha higher than $50^{\circ}$, and about $34 \%$ of men showed alpha in that range. Hack et al. observed increased alpha in $24 \%$ of men. However, they considered an abnormal alpha when greater than 68 degrees 24. Gosvig et al. reported prevalence of increased alpha by approximately $20 \%$ of men $^{25}$. This high prevalence of cases with alpha greater than $50^{\circ}$ in our study corroborates the questioning of Pollard in his study of the suitable value of the alpha angle of $50^{\circ}$ proposed by Nötzli, the former suggesting an acceptable alpha to $62^{\circ 13,18}$.

Increasing the alpha angle was related to decreasing of internal rotation of the hip (IR), $(r=-0355$, $\mathrm{p}<0.001)$.

Despite the correlation between the alpha angle and the internal rotation present is of low intensity, there are reports of a marked decrease in internal rotation in patients with $\mathrm{FAl}^{18}$. Langer et al. described that the resection of the "bump" increased RI by $8^{\circ}$, resection of the "Pincer" by $5^{\circ}$ and when the impingement was mixed, the increase in internal rotation was greater, on average $15^{\circ 26}$. In a casecontrol study, Wyss et al. found a RI average of $4^{\circ}$ in the cases compared with $28^{\circ}$ in the control group, using dynamic MRI study, concluding that the main cause of limitation of internal rotation is the bone impingement, diminishing the importance of soft tissue retraction in limiting the movement ${ }^{27}$.

The average of the anterior femoral head-neck offset was $9.22 \mathrm{~mm}, \mathrm{SD}=2.46$, in agreement with the reference value for normality largest $9 \mathrm{~mm}^{28}$.

Inclusion cysts or herniation pits, reported as indirect signs of Pincer-type impingement, were found in seven hips (8.6\%) in the Dunn $45^{\circ}$ incidence, slightly below the $12 \%$ reported by Ecker in a review of normal contralateral hips in patients who underwent total hip arthroplasty ${ }^{10}$.

We found Came- or Pincer-type radiographic abnormalities in $42.6 \%$ of tests. Acetabular abnormalities were less frequent, accounting for $14 \%$, and the femoral (bulging), were found in $25 \%$ of cases ( 41 hips). The mixed type impingement was found in six cases (3.7\%).

The prevalence of Came-type deformity found among men was 34\% higher than the figures reported in the literature. Doherty et al. observed a prevalence of 3.6\% 29 in a case-control study with over a thousand participants in each group. Another author described prevalence of $12 \%$ in asymptomatic hips ${ }^{10}$. Other authors found a prevalence of $8 \%$ of the Came-type in more than 2,600 skeletons, suggesting that this deformity is considered a normal variation due to the high prevalence in the male population and due to the fact that it alone will not be responsible for the development of hip $\mathrm{OA}^{11}$.

Radiographic changes in the acetabulum which translate Pincer-type impingement, such as the cross sign, were found in 20 hips (12\%), whereas 7\% displayed it bilaterally. The signs of the posterior wall and the of ischial spine were found in $37 \%$ and $30 \%$ of cases, respectively ${ }^{30}$. Hartofilakidis et al. found an even higher prevalence, of $42.7 \%$, in their retrospective series ${ }^{31}$. The prevalence of radiographic signs of acetabular retroversion in the general population cited by Giori et al. was $5 \%$, reaching $20 \%$ in patients with $\mathrm{OA}^{32}$. In a study with symptomatic patients, Allen et al. found signs of acetabular retroversion in $24 \%$ of the sample, in agreement with the study cited above ${ }^{11,32}$. Barros et al. observed a greater number of the crossing sign in controls than in patients, 8.1 and $7.1 \%$, respectively ${ }^{33}$.

The radiographic alteration that caught our attention for its high prevalence was the thigh deep, found in $76 \%$ of cases. Some articles reported a prevalence of $15-19 \%^{11,25}$. Due to the differences found between our results and those in the literature, all radiographs were reassessed six months after collection, following the exact definition of the alteration described extensively in the literature ${ }^{11}$, and the results coincided with the previous findings. We found no justification for this disparity, since our methods for radiographs control were strict.

The average internal rotation was found to be $26^{\circ}$, consistent with normal standards of physical examination of the hip and the work described in the literature, reporting averages of 18-32 ${ }^{\circ 13,15,27}$. However, the rotation in those with alpha greater than or equal to $50^{\circ}$ was significantly lower than in subjects with alpha lower than $50^{\circ}(p=0.002)$. This corroborates the findings of Wyss et al., where the average internal rotation in cases was $4^{\circ}$ and $28^{\circ}$ in controls ${ }^{27}$.

Although Wyss et al. al argue that a hindering of internal rotation is limited by bone structure ${ }^{27}$, we did not find this relationship in the flexion analysis of with the anterior center edge angle (AAC). The expected would be that the greater the $A A C$, the higher the anterior cover and the lower the hip flexion. Nevertheless, our results did not find this association, nor correlated with the cross sign.

Our study has some limitations. The fact that the sample was obtained by convenience, with people linked in some way to the HCPA, cannot compose a representative sample of the normal population. The strong point of this work consists in the systematization and standardization of radiographs, and one of the few studies that used the $45^{\circ}$ Dunn incidence, recommended by Meyers as the most significant way to detect abnormalities in Came-type impingement ${ }^{34}$. 


\section{R E S U M O}

Objetivo: determinar a prevalência dos sinais radiográficos de impacto femoroacetabular (IFA) em adultos assintomáticos e correlacionar com dados do exame físico. Métodos: estudo transversal, com 82 voluntários, 164 quadris, selecionados por conveniência, assintomáticos, entre 40 e 60 anos de idade. Esses foram submetidos à anamnese e exame clínico do quadril, exame radiográfico com três incidências, antero-posterior (AP) de bacia, Dunn a $45^{\circ}$ e falso perfil de Lequesne de cada quadril, para mensuração das variáveis. Aferimos o ângulo alfa, offset anterior do colo femoral, ângulo cérvico diafisário, ângulo CE de Wiberg, índice acetabular, ângulo de Sharp, além dos sinais do cruzamento, da espinha isquiática e da parede posterior. Resultados: nossa amostra foi formada por $66 \%$ de mulheres, com média de idade de 50,4 anos. O ângulo alfa médio foi de 45.10\%, DP = 8.6. 25\% dos quadris apresentaram ângulo alfa maior ou igual a 50\%; entre os homens a prevalência foi $34 \%$ e entre as mulheres $11 \%$. Encontramos sinais radiográficos indicativos de impacto femoroacetabular em 42,6\% dos quadris, sejam eles femorais ou acetabulares, e o aumento do ângulo alfa esteve relacionado com o decréscimo na rotação interna do quadril $(p<0,001)$. Conclusão: Os achados radiográficos de impacto femoroacetabular em pacientes assintomáticos foram frequentes na amostra estudada. 0 aumento do ângulo alfa esteve relacionado com o decréscimo da rotação interna.

\section{Descritores: Impacto femoroacetabular. Quadril. Radiografia. Estudos transversais. Prevalência.}

\section{REFERENCES}

1. Johnston TL, Schenker ML, Briggs KK, Philippon MJ. Relationship between offset angle alpha and hip chondral injury in femoroacetabular impingement. Arthroscopy. 2008;24(6):669-75.

1. Ingvarsson T. Prevalence and inheritance of hip osteoarthritis in Iceland. Acta Orthop Scand Suppl. 2000;298:1-46.

2. Solomon L. Patterns of osteoarthritis of the hip. J Bone Joint Surg Br. 1976;58(2):176-83

3. Clohisy JC, Carlisle JC, Trousdale R, Kim YJ, Beaule PE, Morgan P, et al. Radiographic evaluation of the hip has limited reliability. Clin Orthop Relat Res. 2009;467(3):666-75.

4. Jacobsen S, Sonne-Holm S, Søballe K, Gebuhr P, Lund B. Radiographic case definitions and prevalence of osteoarthrosis of the hip: a survey of 4151 subjects in the Osteoarthritis Substudy of the Copenhagen City Heart Study. Acta Orthop Scand. 2004;75(6):713-20.

5. Kim KC, Hwang DS, Lee CH, Kwon ST. Influence of femoroacetabular impingement on results of hip arthroscopy in patients with early osteoarthritis. Clin Orthop Relat Res. 2007:456:128-32.

6. Lavigne M, Parvizi J, Beck M, Siebenrock KA, Ganz R, Leunig M Anterior femoroacetabular impingement: part I. Techniques of joint preserving surgery. Clin Orthop Relat Res. 2004;(418):61-6.

7. Meyer DC, Beck M, Ellis T, Ganz R, Leunig M. Comparison of six radiographic projections to assess femoral head/neck asphericity Clin Orthop Relat Res. 2006;445:181-5.

8. Bardakos NV, Villar RN. Predictors of progression of osteoarthritis in femoroacetabular impingement: a radiological study with a minimum of ten years follow-up. J Bone Joint Surg $\mathrm{Br}$. 2009;91(2):162-9.

9. Ecker TM, Tannast M, Puls M, Siebenrock KA, Murphy SB. Pathomorphologic alterations predict presence or absence of hip osteoarthrosis. Clin Orthop Relat Res. 2007:465:46-52.

10. Allen D, Beaulé PE, Ramadan O, Doucette S. Prevalence of associated deformities and hip pain in patients with cam-type femoroacetabular impingement. J Bone Joint Surg $\mathrm{Br}$. 2009;91(5):589-94.

11. Leunig M, Beaulé PE, Ganz R. The concept of femoroacetabular impingement: current status and future perspectives. Clin Orthop Relat Res. 2009;467(3):616-22

12. Pollard TCB, Villar RN, Norton MR, Fern ED, Williams MR, Simpson $D J$, et al. Femoroacetabular impingement and classification of the cam deformity: the reference interval in normal hips. Acta Orthop. 2010;81(1):134-41.

13. Tönnis $D$. Normal values of the hip joint for evaluation of $X$-rays in children and adults. Clin Othop Relat Res. 1976:(119):39-47.
14. Clohisy JC, Knaus ER, Hunt DM, Lesher JM, Harris-Hayes M, Prather $\mathrm{H}$. Clinical presentation of patients with symptomatic anterior hip impingement. Clin Orthop Relat Res. 2009;467(3):638-44.

15. Lequesne $M$, DeSeze $S$. Le faux profil du bassin: nouvelle incidence radiographique pour l'étude de la hanche: son utilité dans les dysplasies et les différentes coxopathies. Rev Rheum. 1961;28:64352.

16. Zingg PO, Werner CM, Sukthankar A, Zanetti M, Seifert B, Dora $C$. The anterior center edge angle in Lequesne's false profile view: interrater correlation, dependence on pelvic tilt and correlation to anterior acetabular coverage in the sagital plane. A cadaver study. Arch Orthop Trauma Surg. 2009;129(6):78791

17. Nötzli HP, Wyss TF, Stoecklin CH, Schmid MR, Treiber K, Hodler J. The contour of the femoral head-neck junction as a predictor for the risk of anterior impingement. J Bone Joint Surg $\mathrm{Br}$ 2002;84(4):556-60

18. Siebenrock KA, Kalbermatten DF, Ganz R. Effect of pelvic tilt on acetabular retroversion: a study of pelves from cadavers. Clin Orthop Relat Res. 2003;(407):241-8.

19. Jacobsen S, Sonne-Holm S, Søballe K, Gebuhr P, Lund B. Hip dysplasia and osteoarthrosis: a survey of 4151 subjects from Osteoarthrosis Substudy of the Copenhagen City Heart Study. Acta Orthop. 2005;76(2):149-58.

20. Toogood PA, Skalak A, Cooperman DR. Proximal femoral anatomy in the normal human population. Clin Orthop Relat Res. 2009:467(4):876-85.

21. Pollard TC, Villar RN, Norton MR, Fern ED, Williams MR, Murray DW, et al. Genetic influences in the aetiology of femoroacetabular impingement: a sibling study. J Bone Joint Surg Br. 2010;92(2):20916

22. Neumann M, Cui Q, Siebenrock KA, Beck M. Impingement-free hip motion: the 'normal' angle alpha after osteochondroplasty. Clin Orthop Relat Res. 2009;467(3):699-703.

23. Hack K, Di Primio G, Rakhra K, Beaulé PE. Prevalence of cam-type femoroacetabular impingement morphology in asymptomatic volunteers. J Bone Joint Surg Am. 2010;92(14):2436-44.

24. Gosvig KK, Jacobsen S, Sonne-Holm S, Palm H, Troelsen A. Prevalence of malformations of the hip joint and their relationship to sex, groin pain, and risk of osteoarthritis: a population-based survey. J Bone Joint Surg Am. 2010;92(5):1162-9.

25. Kubiak-Langer M, Tannast M, Murphy SB, Siebenrock KA, Langlotz F. Range of motion in anterior femoroacetabular impingement. Clin Orthop Relat Res. 2007;458:117-24.

26. Wyss TF, Clark JM, Weishaupt D, Nötzli HP. Correlation between internal rotation and bony anatomy in the hip. Clin Orthop Relat Res. 2007:460:152-8. 
27. Maheshwari AV, Malik A, Dorr LD. Impingement of the native hip joint. J Bone Joint Surg Am. 2007;89(11):2508-18.

28. Doherty M, Courtney P, Doherty S, Jenkins W, Maciewicz RA, Muir K, et al. Nonspherical femoral head shape (pistol grip deformity), neck shaft angle, and risk of hip osteoarthritis: a casecontrol study. Arthritis Rheum. 2008;58(10):3172-82.

29. Werner CM, Copeland CE, Ruckstuhl T, Stromberg J, Turen CH, Kalberer $F$, et al. Radiographic markers of acetabular retroversion: correlation of the cross-over sign, ischial spine sign and posterior wall sign. Acta Orthop Belg. 2010;76(2):166-73.

30. Hartofilakidis G, Bardakos NV, Babis GC, Georgiades G. An examination of the association between different morphotypes of femoroacetabular impingement in asymptomatic subjects and the development of osteoarthritis of the hip. J Bone Joint Surg Br. 2011;93(5):580-6.

31. Giori NJ, Trousdale RT. Acetabular retroversion is associated with osteoarthritis of the hip. Clin Orthop Relat Res. 2003;(417):263-9.

32. Barros HJ, Camanho GL, Bernabé AC, Rodrigues MB, Leme LE. Femoral head-neck junction deformity is related to osteoarthritis of the hip. Clin Orthop Relat Res. 2010;468(7):1920-5.
Received on 30/10/2012

Accepted for publication 20/12/2012

Conflict of interest: none.

Source of funding: none.

\section{How to cite this article:}

Scheidt RB, Galia CR, Diesel CV, Rosito R, Macedo CAS. Prevalência dos achados radiográficos de impacto femoroacetabular em adultos assintomáticos. Rev Col Bras Cir. [periódico na Internet] 2014;41(1). Disponível em URL: http://www.scielo.br/rcbc

Address for correspondence:

Rodrigo Benedet Scheidt

E-mail: rodrigoscheidt@hotmail.com 